\title{
CÂMBIO FLUTUANTE E BALANÇO DE PAGAMENTOS Uma Análise Preditiva
}

\author{
Clarice PECHMAN* \\ Rodolfo GRANDI**
}

\begin{abstract}
RESUMO: O artigo se divide em quatro itens. No primeiro aborda-se o balanço de pagamentos e o câmbio flutuante; apresenta-se inicialmente um histórico dos dados de viagens internacionais no balanço de pagamentos do Brasil, seguido da análise da característica sazonal do turismo e de consideraçōes sobre o câmbio turismo. O segundo item trata da correlação entre a entrada de turistas e as receitas de viagens internacionais. O terceiro item apresenta uma tentativa de previsão para a entrada de turistas estrangeiros no Brasil e comenta os resultados alcançados. Finalmente as conclusōes são apontadas, sugerindo que o próximo passo seja prever o saldo do item viagens internacionais do balanço de pagamentos, com vistas à tomada de decisão sobre a política de desenvolvimento setorial do turismo estrangeiro no País.
\end{abstract}

UNITERMOS: Turismo: dólar turismo; balanço de pagamentos; sazonalidade. Dólar turismo: câmbio; mercado paralelo de dólares.

Balanço de pagamentos: entrada de turistas estrangeiros; receitas de viagens internacionais; previsão por série de tempo.

ABSTRACT: The paper is divided into four parts. The first one investigates the cmpirical eridence for the balance of payments and the fiee floating exchange rate market. A historical analysis of the data on tourism according to the Brazilian balance of payments is followed by the analvsis of the seasonal pattem of the data and by considerations on a frec floating exchange rate for tourism. The second part investigates the correlation betwecn the inflow of tourists and the reccipts from international travel. The third part of the paper is an attempt to forecast the inflow of forcign tourists to Brazil; we discuss the estimates obtained. Finally the conclusions are pointed out and suggest that the next step is to forecast the balancc of the tourism account in the balance of payments as a tool for policymakers to decide on the development of the tourism industry in Brazil.

(*) Diretora-Executiva da Anecc - Associação Nacional de Empresas Credenciadas em Câmbio e Diretora-Presidente do BEE - Bureau de Estatística e Econometria.

End. para corresp.: Anecc - Rua Primeiro de Março, n 23 - $3^{\circ}$ andar - CEP 20010 Rio de Janeiro - RJ - Brasil.

(**) Consultor da Anecc e Gerente de Projetos do BEE.

End. para corresp.: Anecc - Rua Primeiro de Março, nº 23 - $3^{\circ}$ andar - CEP 20010 -

Rio de Janeiro - RJ - Brasil. 


\section{BALANÇO DE PAGAMENTOS E CÂMBIO FLUTUANTE}

\subsection{Histórico}

O histórico dos dados de Viagens Internacionais no Balanço de Pagamentos do Brasil, conforme evidenciam a Tabela 1 e a Figura 1 que apresentamos a seguir, atesta um saldo entre receitas e despesas sistematicamente negativo, para o período entre 1982 e 1988, apenas revertendo-se a partir do primeiro trimestre de 1989. Em cada um dos trimestres de 1989, ao contrário dos resultados correspondentes aos períodos anteriores, o saldo do item Viagens Internacionais no Balanço de Pagamentos mostra-se superavitário e, ademais, crescente.

Por trás desta evidência está, particularmente, a política de câmbio no Brasil e a prática cambial decorrente pelo segmento do Turismo. A política de câmbio controlado, regido por um sistema de minidesvalorizaçōes desde 1968, que se estendeu, com raras exceçōes, até 1989, garantiu historicamente que os dólares trazidos por turistas estrangeiros ao Brasil se notabilizassem como fonte direta de abastecimento do mercado paralelo de dólares no País.

É notória, e já apontada em diversos trabalhos sobre a matéria ${ }^{1.2}$, a divergência das estatísticas apresentadas sobre receita com viagens internacionais pelo Banco Central do Brasil, de um lado, e pela Embratur - órgão federal oficial de turismo, de outro. A diferença entre as apuraçōes pelo Banco Central e pela Embratur foi, tradicionalmente, sistematica e expressiva. A título de exemplo, em 1984 a estatística apresentada pelo Banco Central no caso da receita com viagens internacionais representou tão-somente $2,5 \%$ do valor correspondente estimado pela Embratur. A diferença decorrente tomou o caminho do mercado paralelo de dólares; não só no ano de 1984, mas em todo o período que precedeu a 1989, quando da criação e subseqüente implementação do mercado de taxas flutuantes de câmbio (câmbio tu: rismo). As estimativas francamente divergentes nos permitiram inferir que mais de $40 \%$ do próprio movimento do mercado paralelo teve origem no turismo.
TABELA 1 - Viagens internacionais e balanço de pagamentos

\begin{tabular}{|c|c|c|c|c|c|}
\hline$A N O$ & Trimestre & Turistas $^{a}$ & $\begin{array}{l}\text { Receita } \\
\text { (US\$ } \\
\text { milhöes) }\end{array}$ & $\begin{array}{l}\text { Despesa } \\
\text { (US\$ } \\
\text { milhöes) }\end{array}$ & Saldo \\
\hline \multirow[t]{4}{*}{1982} & 1 & 6330 & 20,6 & 112,8 & $-92,2$ \\
\hline & II & 3531 & 18,0 & 279,5 & $-261,5$ \\
\hline & III & 2101 & 14,9 & 359,8 & $\begin{array}{l}-344.9 \\
\end{array}$ \\
\hline & IV & 4384 & 11,9 & 158,7 & $-146,8$ \\
\hline \multirow{4}{*}{1983} & I & 5952 & 10,2 & 120,2 & $-110,0$ \\
\hline & II & 2698 & 9,7 & 123.3 & -113.6 \\
\hline & III & 9,2 & 125,4 & $-116,2$ & \\
\hline & IV & 6189 & 10,1 & 52,3 & $-42,2$ \\
\hline \multirow[t]{4}{*}{1984} & I & 9245 & 11,9 & 43,1 & -31.2 \\
\hline & II & 4795 & 18,3 & 54.0 & $-35,7$ \\
\hline & III & 4428 & 17.7 & 62.5 & -44.8 \\
\hline & IV & 7674 & 17,1 & 58,0 & $-40,9$ \\
\hline \multirow[t]{4}{*}{1985} & I & 9685 & 17,2 & 78,9 & -61.7 \\
\hline & II & 4877 & 14,9 & 112,5 & $-97,6$ \\
\hline & III & 4400 & 16,0 & 148.9 & -1.32 .9 \\
\hline & iv & 8712 & 17,7 & 101,0 & $-83,3$ \\
\hline \multirow[t]{4}{*}{1986} & I & 11251 & 17,3 & 97,5 & $-80,2$ \\
\hline & II & 6457 & 19,0 & 168,5 & -149.5 \\
\hline & III & 6984 & 24,3 & 196.6 & -172.3 \\
\hline & IV & 11732 & 24,3 & 131,5 & $-107,2$ \\
\hline \multirow[t]{4}{*}{1987} & I & 13026 & 22,1 & 103.5 & $-81,4$ \\
\hline & II & 10691 & 24,8 & 55.8 & $-31,0$ \\
\hline & III & 6113 & 26,6 & 66,7 & -40.1 \\
\hline & IV & 12534 & 28,3 & 59,6 & $-31,3$ \\
\hline \multirow[t]{4}{*}{1988} & I & 13031 & 25,9 & 121.6 & -95.7 \\
\hline & II & 9009 & 26,5 & 187,1 & $-160,6$ \\
\hline & III & 7905 & 32,1 & 213,4 & -181.3 \\
\hline & IV & 14152 & 32,5 & 183,4 & -150.9 \\
\hline \multirow[t]{4}{*}{1989} & 1 & 12503 & 162,1 & 113,8 & 48.3 \\
\hline & II & 8733 & 323,0 & 208.6 & 114.4 \\
\hline & III & 8285 & 362,3 & 233,7 & 128.6 \\
\hline & IV & 11134 & 376.5 & 193.9 & 182.6 \\
\hline
\end{tabular}

(a) A coluna "turistas" refere-se à entrada de turistas em vôos charters para o Rio de

Fontes: Banco Central do Brasil; H. Stern Com. e Ind. 


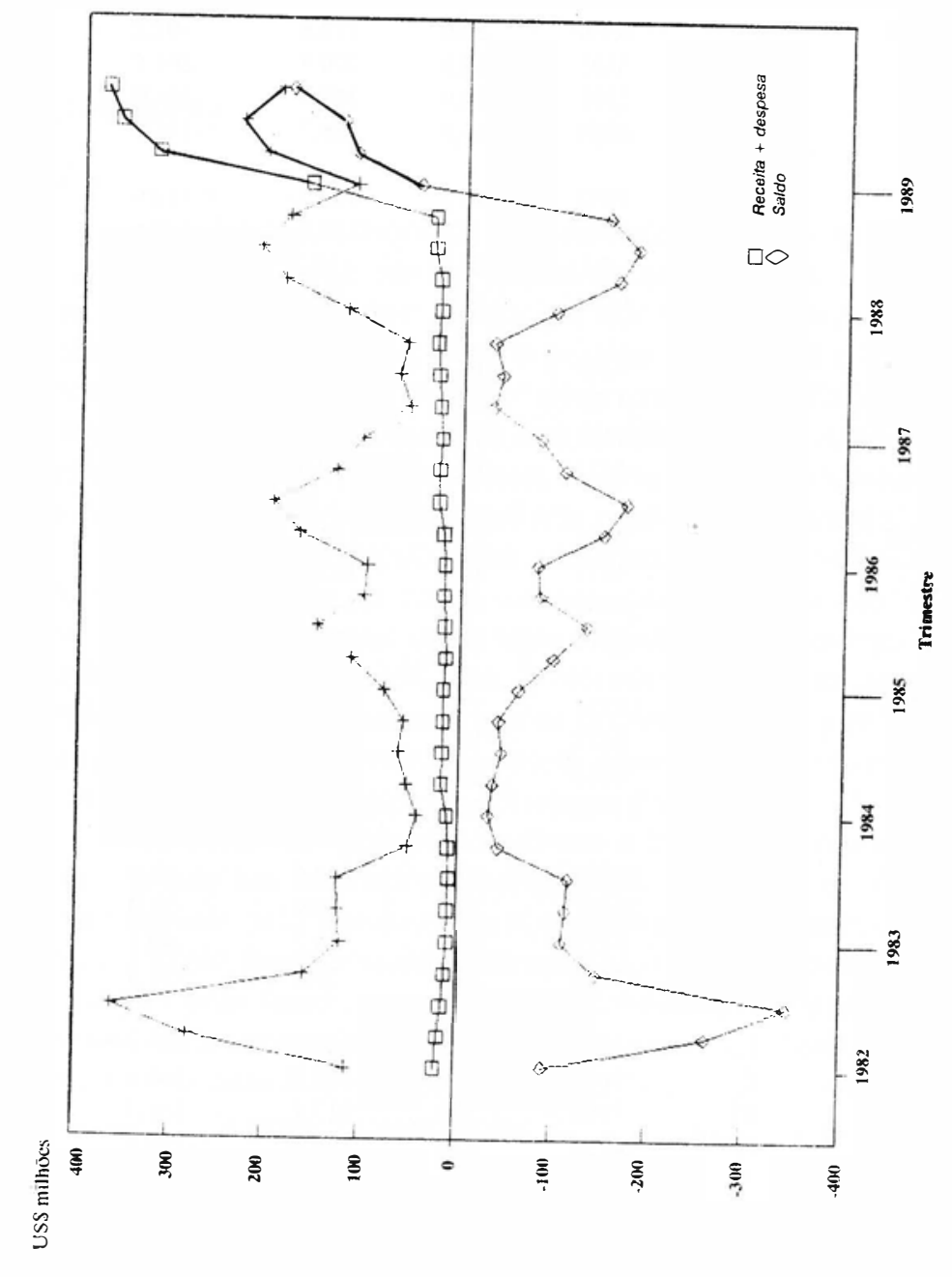

Claramente as metodologias de apuração dos dados estatísticos por cada uma das instituições aqui referidas diferem entre si. O Banco Central reúne os dados a partir do registro das operações de câmbio oficialmente realizadas por turistas. A Embratur baseia seus resultados em pesquisas que promove sobre os gastos totais dos turistas estrangeiros no Brasil, e a sua permanência média, realizadas junto aos principais pontos de entrada (aéreos e terrestres) do País, em conjunto com as informações que o órgão oficial de turismo recebe da Polícia Federal.

Vale acrescentar que, embora a divergência entre as metodologias tenha gerado estimativas de receita pela Embratur como viagens internacionais muito superiores àquelas do Banco Central, é bem possível que mesmo as despesas dos turistas estrangeiros no Brasil estimadas pela Embratur estejam aquém do seu valor efetivo. Isto porque o controle das entradas e saídas de caixa por parte do órgão competente de fiscalização é feito através das declarações dos contribuintes para fins de imposto de renda; e a sonegação na área hoteleira é reconhecidamente elevada. Muitas vezes os pagamentos são feitos a um agente do próprio hotel no exterior, que, após retirar a parcela correspondente à sua comissão, deposita em conta bancária o saldo restante em nome de quem de direito. $O$ turista em questão não é incluído, evidentemente, no cálculo da taxa de ocupação do hotel, não sendo, portanto, hóspede para efeito de registro. Este é apenas um dentre tantos outros expedientes praticados na área de turismo, todos eles levando a uma subestimação considerável dos gastos incorridos pelos turistas estrangeiros no Brasil.

Até a criação e a disseminação do mercado de taxas flutuantes de câmbio (câmbio turismo) em janeiro/1989, o fato é que, com poucas horas no Brasil, o visitante estrangeiro descobria - isto quando já não sabia antes de desembarcar - que poderia trocar seus dólares por muito mais cruzeiros do que o câmbio oficial permitia. A maneira mais corrente de fazê-lo era vender as divisas nas portarias dos hotéis, onde funcionários recebiam cruzeiros dos cambistas para comprar os dólares dos hóspedes.

\subsection{Sazonalidade}

A relação entre a entrada de turistas estrangeiros no Brasil e o mercado paralelo de dólares foi historicamente tão marcante a ponto de um mercado transferir para o outro a sua própria sazonalidade. As- 
sim, a característica sazonal do mercado paralelo de dólares no Brasil foi o padrão sazonal das entradas líquidas devidas ao turismo, especialmente ao de argentinos. A estação de turismo ocorre no começo do ano, desde as vésperas do Natal até após o Carnaval, havendo outro período mais curto em julho. Nesses meses, verifica-se uma taxa de entrada sazonalmente elevada no mercado negro, que provoca um acúmulo sazonal de dólares e um declínio sazonal do ágio do dólar paralelo em relação ao câmbio oficial. Como esse fator sazonal é perfeitamente previsível, porque as férias escolares, assimo como o Carnaval, acontecem sempre por essa época do ano, ele não ocasiona saltos no ágio, que só ocorrem no caso de alguma novidade para a qual as pessoas não estejam preparadas, mas sim um movimento gradual.

O evento de uma estação sazonal afeta a conta corrente do mercado negro, mas não o equilíbrio no mercado de ativos. Com isto, as combinações de estoque e ágio do mercado negro que já equilibravam o mercado de ativos continuam a ser responsáveis pela evolução do ágio. A dificuldade para explicar-se o fator sazonal do ágio é a de que não se tem um ponto natural de início. Apesar disso, iremos supor que nos encontramos, precisamente, no ponto de pico do ágio, pouco an tes da estação de turismo. O ágio apresenta-se estável, tendo alcançado seu nível máximo paralelamente com a queda no estoque de dólares: poucos turistas geram, conseqüentemente, um mercado de poucos dólares. Neste momento, então, os portadores de carteira dão-se conta da iminente estação de turismo e da previsível acumulação de dólares do mercado negro. Em reação, o ágio começa a cair, induzindo, portanto, ao desacúmulo de dólares, antes mesmo da estação de turismo. Depois de atingido um nível mínimo de estoque de dólares, os turistas, de fato, começam a chegar e o reabastecem. O ágio continua a cair, de início mais rapidamente e, aos poucos, mais devagar, até alcançar seu nível mínimo. O estoque de dólares continua aumentando, mas agora o ágio também sobe.

Apenas para ilustrar o processo acima descrito, poderíamos imaginar que estivéssemos traçando, com um fio de barbante, uma trajetória oval em torno de um eixo, numa espécie de moto contínuo, sem princípio nem fim, e sempre em um único sentido. Ora a trajetória passa por cima, ora por baixo do eixo. Entre uma situação e outra, o fio cruza o eixo que, por sua vez, conhecidas as taxas de juros nominais interna e externa, bem como a taxa de desvalorização cambial para o período em questão, é o resultado de todas as combinações de nível de ágio e de nível de estoque de dólares do mercado negro que garantem um mercado de ativos equilibrado. Cada trajetória completa corres- ponde ao movimento sazonal anual, e que se repete sempre, nos anos seguintes, tendo-se igualmente verificado nos anos anteriores.

É inieressante ressaltar que também ocorre um padrão sazonal na taxa de variação do ágio. Nos períodos em que a oferta relativa de dólares é alta e crescente, a taxa de aumento do ágio precisa acelerarse e, inversamente, quando a oferta relativa é baixa e decrescente, o ágio cai a uma taxa crescente. Assim, a partir do pico sazonal, o ágio cai, tal como o estoque de dólares do mercado. Portanto, antes da estação de turismo, e dai por diante, a taxa de declínio do ágio aumenta. Quando o nível do estoque atinge um mínimo, encontramo-nos na própria estação, e o grande influxo sazonal de dólares dos turistas neutraliza o esgotamento induzido pelo baixo ágio sazonal. Durante uma fase da estação sazonal, o estoque de dólares aumenta, do mesmo modo que a oferta relativa de dólares, até atingirmos, momentaneamente, o equilíbrio do mercado de ativos correspondente a uma taxa de variação nula do ágio. Por conseguinte, a taxa de declínio do ágio reduzse na estação de turismo. Dando continuidade ao processo, o ágio sazonalmente baixo induz a um amplo esgotamento, que mal é neutralizado pelas grandes entradas sazonais devidas aos turistas, e a taxa de crescimento do ágio atinge o seu máximo. Daí em diante, a oferta relativa de dólares cai, tal como a taxa de crescimento do ágio. Embora os níveis de estoque mínimo e máximo de dólares sejam alcançados na própria estação de turismo, sua posição relativa depende do padrão particular dos influxos devidos aos turistas. O ponto no tempo em que o estoque mínimo é atingido precede o pico do ágio, enquanto o ponto no tempo em que se observa um estoque máximo de dólares lhe é posterior, como se evidencia pelo fato de que o esgotamento do estoque é tanto mais elevado quanto menor for o ágio. Estes dois instantes poderão estar muito próximos entre si no tempo, se as entradas devidas aos turistas se concentrarem marcantemente, ou muito distantes um do outro, se os fluxos de dólares dos turistas se distribuirem de modo regular.

\subsection{Câmbio Turismo: Uma Ruptura com o Passado Distorcido}

A partir de 09/01/1989, no que diz respeito às operações combiais, inerentes ao segmento do turismo, inaugurou-se um novo mercado oficial, com taxas flutuantes de câmbio, cujos participantes passaram a incluir as agências de viagem, os hotéis, além de distribuidoras e corretoras de valores e câmbio, bancos múltiplos e bancos comerciais, 
devidamente credenciados pelo Banco Central do Brasil a operar neste mercado. A consolidação do câmbio turismo desde a sua criação é um fato: segundo dados divulgados pela Anecc - Associação Nacional das Empresas Credenciadas em Câmbio -, o mercado tem um movimento de giro diário de cerca de US\$300 milhões entre compra e venda, com aproximadamente 650 empresas credenciadas a operar.

Desde 1989, conseqüentemente, no que se refere ao turismo, o papel que era do mercado paralelo de dólares perdeu expressão e mais do que isso, caiu por terra a distorção que aquele mercado gerava nos dados de receita de viagens internacionais conforme contabilizados pelo Banco Central. A Figura 1 (p. 22) mostra o salto que se verifica a partir do $1^{\circ}$ trimestre de 1989 , tanto na receita quanto no saldo correspondente, comparativamente a todo o período precedente entre 1982 e 1988 apresentado. Confirmadamente, o que era défict sistemático no passado, torna-se superávit em 1989.

\section{ENTRADA DE TURISTAS E RECEITA COM VIAGENS} INTERNACIONAIS

Na Tabela 1 (p. 21) apresentamos uma coluna denominada "turistas" referente à quantidade de turistas estrangeiros que ingressaram no Rio de Janeiro, em vôos charters, no periodo entre o $1^{\circ}$ trimestre de 1982 e o $4^{\circ}$ trimestre de 1989 . Obviamente trata-se de uma série histórica de escopo limitado; contudo, foi aqui utilizada em vista da sua confiabilidade, por um lado, e também por ser o Rio de Janeiro o principal portão de entrada no País.

A Figura 2 reproduz essa série até o $4^{\circ}$ trimestre de 1988 e revela, em linha com o segmento do turismo como um todo, um padrāo sazonal inegável. Se esta sazonalidade é marcante na série de entrada de turistas, o padrão sazonal da receita com viagens internacionais é menos evidente, conforme se depreende dessa Figura. De toda maneira, de se esperar existir uma correlação entre a entrada de turistas, mesmo com as restrições implícitas à série aqui utilizada, e a receita com viagens internacionais conforme contabilizada pelo Banco Central, apesar de subestimada relativamente às estatísticas da Embratur. Em vista da mudança estrutural ocorrida em janeiro de 1989, com a criaçāo do câmbio turismo, restringimos a análise sobre a referida correlação entre as séries ao período até o $4^{\circ}$ trimestre de 1988.

A medição da correlação entre receita e entrada de turistas es trangeiros foi obtida, de forma simplificada, pelo coeficiente de corre-

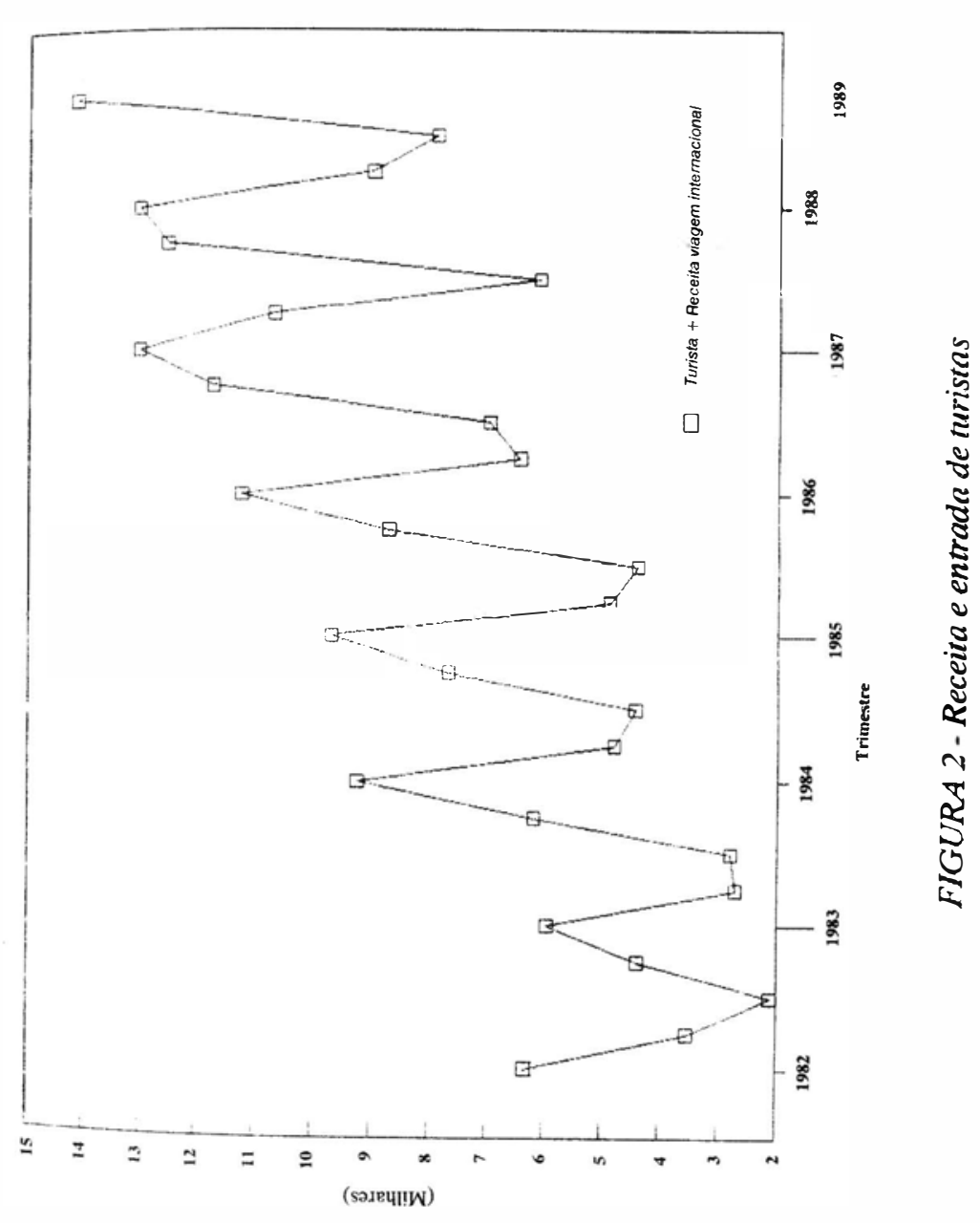


lação definido como o quociente entre a covariância entre os elementos correspondentes das duas séries de dados, e o produto dos desvios-padrão de cada uma delas. Tal coeficiente foi da ordem de 0,6, o que corresponde a dizer que há uma relação direta entre as duas séries consideradas de cerca de $40 \%$. Este resultado parece-nos indicar que a busca de uma previsão para o comportamento da receita com viagens internacionais pode parțir de uma previsão precedente para a entrada de turistas estrangeiros.

O resultado numérico do coeficiente de correlação em questão deve melhorar, na medida em que nos seja possível ter em mãos uma série longa de dados de receita com viagens internacionais, já sob o novo regime cambial inaugurado com as taxas de câmbio flutuantes (câmbio turismo). Isto se verificando, a capacidade de previsão do próprio saldo entre receitas e despesas com viagens internacionais também se elevará, podendo servir de instrumento de decisão sobre a política de desenvolvimento setorial do turismo no País.

\section{ENTRADA DE TURISTAS: UMA TENTATIVA DE PREVISÃO}

Diante do que expusemos e das precariedades impostas, a Anecc - Instituição que congrega o universo dos agentes que operam no mercado de taxas flutuantes de câmbio -, através de seu Boletim Técnico mensal vem apresentando projeçōes mensais para a entrada de turistas estrangeiros no Rio de Janeiro com base nos dados fornecidos pela $\mathrm{H}$. Stern Com. e Ind. Fazendo uso da mesma base de dados e da mesma técnica de previsão, optamos aqui pela periodicidade trimestral aplicada ao período entre o $1^{\circ}$ trimestre de 1980 e o $2^{\circ}$ trimestre de 1990.

O modelo mais adequado para previsōes de curto prazo, neste caso, é o modelo de série de tempo de Box \& Jenkins do tipo Sarima. A especificação que melhor se ajustou aos dados foi um Sarima $(1,0,0)$ $(1,0,0) 12$. Ou seja, o modelo é autoregressivo de $1^{\mathrm{a}}$ ordem e sazonal com defasagem de 4 períodos (1 ano). O modelo não apresentou tendência, nem média móvel dos erros.

Os parâmetros gerados pelo modelo tiveram como base o período até o $2^{\circ}$ trimestre de 1990 . Conseqüentemente, as projeçōes para os dois últimos trimestres de 1990 também foram geradas pela mesma base. O modelo estimado nos forneceu um passo à frente $\left(3^{\circ}\right.$ trim/1990) e dois passos à frente (4º trim/1990), sempre apontando uma projeção média, mais provável, entre um limite inferior (mínimo) e um limite superior (máximo), considerando-se um intervalo de confianças de $95 \%$.

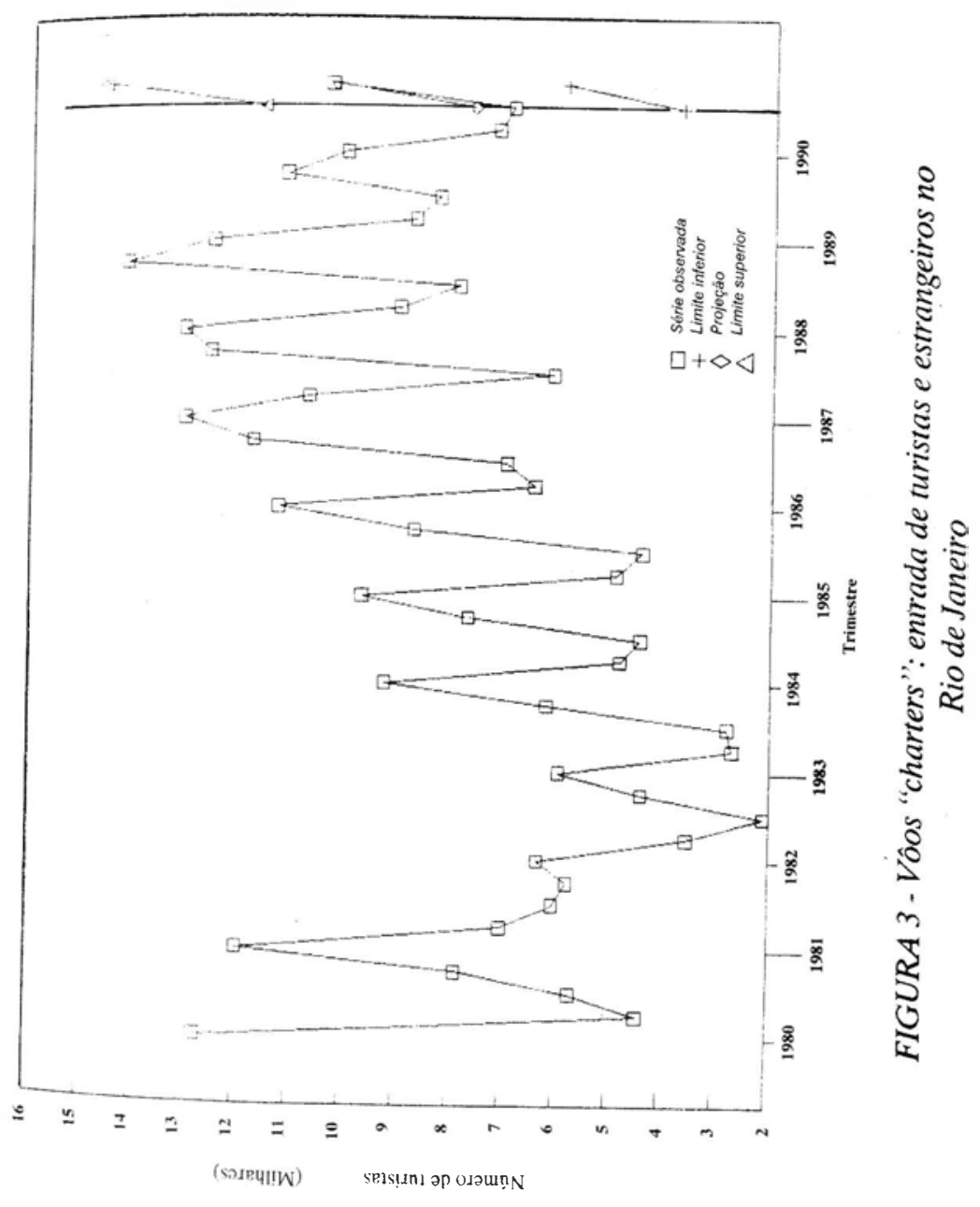


Assim, a leitura da Figura 3 deve-se fazer da seguinte forma: para o $3^{\circ}$ trimestre de 1990 , a projeção indicou um resultado mais prová. vel de 7.647 turistas, com limite inferior de 3.721 e um limite superior de 11.573 turistas. O resultado efetivamente observado foi de $6.922 \mathrm{tu}$ ristas, indicando um erro de previsão não superior ao entorno de $10 \%$. Para o $4^{\circ}$ trimestre, a projeção apontou uma entrada mais provável de 10.242 turistas, dentro de um intervalo entre 5.890 e 14.606 turistas. O valor observado no $4^{\circ}$ trimestre foi de 10.311 turistas, indicativo de um erro de previsão inferior a $1 \%$.

Face aos resultados obtidos, apenas com o passado da própria série de entrada de turistas estrangeiros é possível fazer-se previsão, a curto prazo, com robustez, pelo menos até dois períodos à frente.

\section{CONCLUSÃO}

Sinteticamente, este artigo procurou associar a prática cambial histórica no segmento de turismo à política global de câmbio no Brasil, caracterizando os dólares trazidos pelos turistas estrangeiros como fonte direta de abastecimento no mercado paralelo de dólares no País.

O padrão sazonal do turismo e do mercado paralelo de dólares foi descrito. A partir de janeiro/1989 inaugurou-se o novo mercado de taxas flutuantes de câmbio (câmbio turismo), pondo fim à distorção histórica no registro pelo Banco Central do Brasil dos dados sobre receita com viagens internacionais da balança de pagamentos.

Trabalhando-se com dados trimestrais no período 1982-88, apesar das distorções na série sobre receita com viagens internacionais, pré-câmbio turismo, identifica-se uma correlação satisfatória entre esta série e outra de entrada de turistas enstrangeiros no Rio de Janeiro em vôos charters.

Utilizando-se um modelo de série de tempo, com base na série de dados trimestrais entre 1980 e o $2^{\circ}$ trimestre de 1990 da entrada de turistas estrangeiros no Rio de Janeiro, foram obtidas previsōes, robustas, de curto prazo. Tais resultados, somados à nova realidade do câmbio turismo a partir de janeiro/1989, nos levam a crer que o próximo passo desta trajetória seja a formulação de previsóes de curto prazo para receita, despesa e saldo do item viagens internacionais do balanço de pagamentos, como instrumento de decisão sobre a política de desenvolvimento setorial do turismo estrangeiro no Brasil.

\section{REFERÊNCIAS BIBLIOGRÁFICAS}

1. PECHMAN, C. O dólar paralclo no Brasil. Paz e Terra, 1984. 2. ed.

2. RABAHY, W. A. Planejamento do Turismo - Estudos económicos e fundamentos econométricos. São Paulo, Loyola, 1990,167 p. 